\title{
Use of complementary and alternative medicine in Norwegian hospitals
}

\author{
MED - 3950 \\ 5. - årsoppgave
}

Profesjonsstudiet i medisin ved

Universitetet i Troms $\varnothing$.

Renate Jacobsen MK-08

Veileder: Agnete Kristoffersen

Troms $\varnothing 30.05 .13$

Key words: CAM, hospitals, Norway, trends 


\section{Table of contents}

ABSTRACT

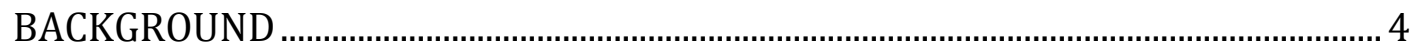

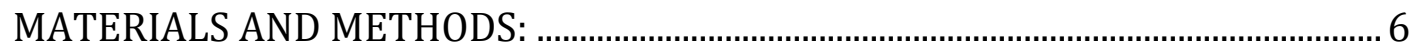

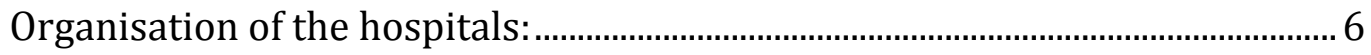

The questionnaire

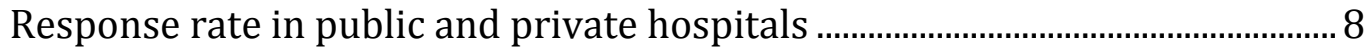

Response rate in different parts of Norway .............................................................. 9

Statistical methods:

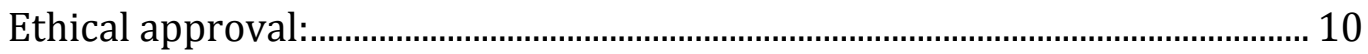

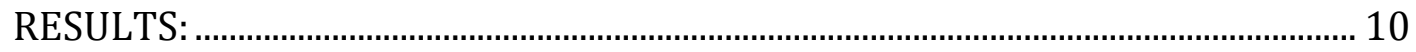

Basic characteristic of the participants: …….................................................... 10

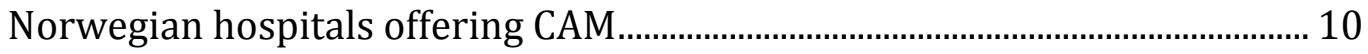

CAM offered in somatic and psychiatric hospitals................................................ 10

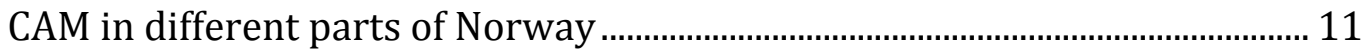

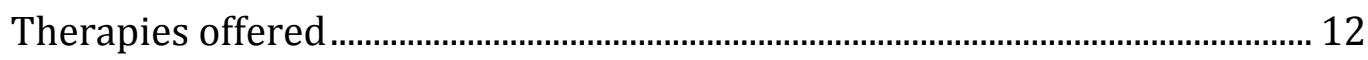

CAM offered in Norwegian hospitals in 2013 compared to 2008: .................. 12

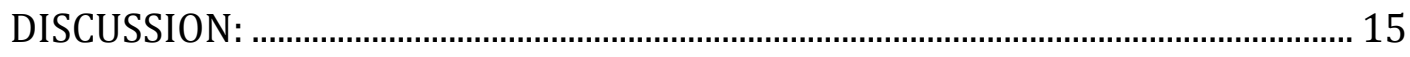

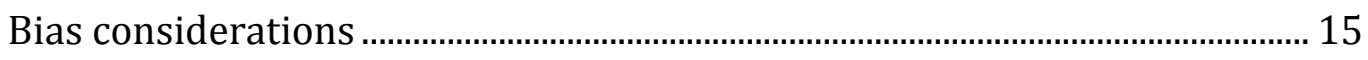

Comparison of CAM offered within different types of hospitals ..................... 16

Comparison of CAM offered within different parts of Norway ......................... 16

Comparison of CAM offered within Norwegian hospitals in 2008 and 2013: 16

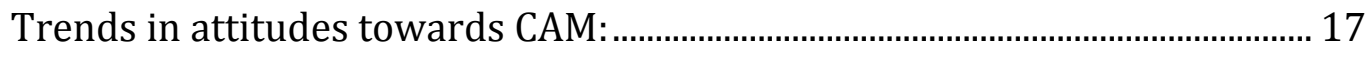

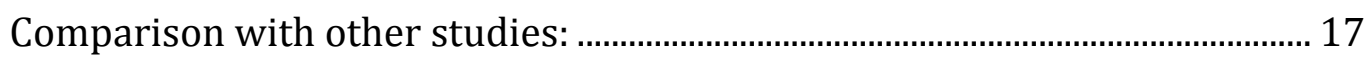

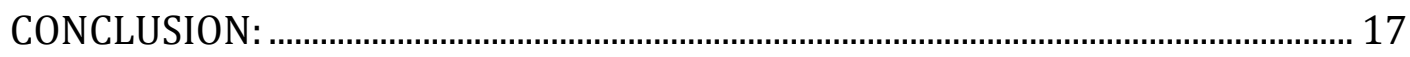




\section{ABSTRACT}

Background: During the last decades the use of CAM inside and outside public health care has had a prominent increase. The National Research Centre in Complementary and Alternative Medicine (NAFKAM) has studied the tendency of CAM offered within the Norwegian hospitals since 2001. The aim of this study is to (1) describe the number of Norwegian hospitals offering CAM, (2) compare the use in different kinds of hospitals and in different regions, and (3) describe the changes in hospitals offering CAM since the first and second survey in 2001 and 2008.

Methods: In January 2013, 80 hospitals received a one-page questionnaire asking about CAM offered in their hospital. Out of these 59 (73.8\%) responded, and make the basis for the analyses.

Results: The study has shown that $64.4 \%$ of Norwegian hospitals offer CAM to their patients. No major differences were found between public and private hospitals and between somatic and psychiatric hospitals. Private psychiatric hospitals have the highest frequency of use of $80 \%$. There were some regional differences, however not at a significant level. Acupuncture is the most often used CAM method, followed by art- and expression therapy and massage. Hospitals offering CAM has increased from $25 \%$ in 2001 to $50.5 \%$ in 2008 and $64.4 \%$ in 2013.

Conclusions: There has been a significant increase in the total number of Norwegian hospitals offering CAM since 2001, both within public and private, somatic and psychiatric hospitals. 


\section{BACKGROUND}

During the last decades there has been a substantial increase in the use of complementary and alternative medicine (CAM) outside the health care system [1-4]. Several international studies have demonstrated this gain in use and interest in the general population, as well as in different patients groups [1-7].

A recent international systematic review of trends in use of CAM in a general population, found a considerable use of CAM in all 15 countries surveyed [7]. The review was based on published studies from nine databases from 1998 onwards. Prevalence of CAM use during the last 12 months ranged from $9.8-76 \%$ [7]. The prevalence of ever use of CAM in the Scandinavian countries ranged between 34$49 \%$ in a survey published in 2005 [4].

In Norway a recent survey show that $45.3 \%$ of the participants had used CAM within the last 12 months. The use of CAM seemed to be unchanged since 2007 [8]. Massage was the most often used CAM method, followed by acupuncture $[1,8,9]$.

A study describing use of CAM inside and outside Norwegian hospitals showed that $48.7 \%$ of the respondents had received CAM within the last 12 months, inside or outside the health care system. The survey was based on telephone interviews with Norwegians above 15 years of age, living in private households, with a cell phone or a landline telephone. The results from this study indicated that the patients combined conventional medicine and CAM, and did not see themselves as belonging to one or the other type of system. They make their own health care by combining the two systems [1].

A survey regarding attitude towards, and use of CAM among different occupational groups within hospitals in north of Norway, show a far more positive attitude towards CAM among office staff and nurses (71-72\%), than among medical doctors (16\%) [9, 10]. Nurses and young female in all occupational groups were most positive to the use of CAM. They were also more interested in knowledge and information about CAM. The trend seems to be that more females become doctors, and more nurses get into leading positions, which probably consolidate the total attitude towards CAM within the public health care system in the future [10]. 
Personal use of CAM by U.S. health care workers showed that health care workers are more likely to use CAM than the general employed population. The health conditions most often leading to the use of CAM was back, neck and joint pain. The survey did show evidence that the attitude towards integration of CAM into the health care practice, and referral for CAM to patients, were influenced by health care workers personal use of CAM [11].

As the request for CAM continues to increase, health care systems seem to integrate some of these therapies into conventional medical care $[9,12]$.

A study from 2008 showed that $51 \%$ of general practitioners physicians and specialists in Germany were in favour of CAM. The most frequently prescribed methods were physical therapy, phytomedicine, exercise, nutrition, massage and relaxation techniques [2].

Acupuncture has been an integrated part of the clinical practise for Norwegian general practitioners (GPs) with acupuncture training. One survey found that out of the 111 GPs with acupuncture training answering the questionnaire, $60 \%$ of them used acupuncture to treat patients. Further results showed that $52 \%$ used acupuncture in more than $5 \%$ of the consultations. Acupuncture is most often used to treat muscle and skeletal pain, migraine and tension headache, but also used on patients with nausea, indigestion, allergies, asthma and sleeping disorders. Effect was reported in 3 out of 4 patients [13].

In some countries the use of CAM is well integrated into the general health care system. One example is Washington State, where $86 \%$ of the hospices offered CAM to their patients. The therapies were offered by volunteers and were not covered under hospice benefits [14]. Interest from the patients and improvement in quality of life in end-of-life care, was the main reason for the high number of hospices offering CAM [14].

A recent study among paediatric outpatients in ten hospital clinics in Canada found that $42-71 \%$ of the patients used CAM in addition to conventional medicine. Most respondents reported helpful use of CAM and with none or few negative effects [5].

The Royal London Hospital for Integrated Medicine (RLHIM) has offered alternative medicine to their patients for more than 160 years, and is the largest public hospital in 
England offering CAM. The hospital has been acknowledged by the National Health Service since 1948, and was in 2002 integrated as a part of The University College London Hospitals [15]. The treatment of patients finds place in policlinics run by medical doctor specialists [15]. The hospital combines traditional and alternative treatment, and has a close collaboration with other university hospitals according to the treatment of patients. In Norway, on the other hand, there are no public policlinic practice offering mainly CAM [15]. However, several of the Norwegian public and private hospitals still seems to integrate use of alternative medicine, especially acupuncture, during delivery [16]. In general the patients demand is often the main reason why a hospital decides to provide a specific type of CAM therapy [12]. In a Swiss study of CAM within hospitals, 33\% reported offering of CAM to patients [17]. The offering of CAM in Norwegian hospitals has been studied twice by NAFKAM, in 2001 and 2008. From 2001 to 2008 the use of CAM in Norwegian hospitals increased substantially from $25 \%$ in 2001 to $50.5 \%$ in 2008 [16, 18], finding acupuncture as the most used therapy $[16,18]$. The aim of this study is to (1) describe the number of Norwegian hospitals offering CAM, (2) compare the use in different kinds of hospitals and in different regions, and (3) describe the changes in hospitals offering CAM since the first and second survey in 2001 and 2008.

\section{MATERIALS AND METHODS:}

\section{Organisation of the hospitals:}

In Norway the public secondary and tertiary health care service are divided into four regional health authorities. These regional health authorities are responsible for the health care service in a given part of the country. Each of the regional health authorities is divided into smaller local health units, which again is responsible for one or more smaller hospitals, with both somatic and psychiatric sections. The health authorities are drifted by the government, and are part of the public health service. During the first decade of the $21^{\text {st }}$ century there has been a merger of many small public hospitals to fewer, bigger hospitals. The total number of Norwegian public hospitals has thereby decreased. In addition to the public hospitals, there are several 
smaller private hospitals, both somatic and psychiatric. Some of these have funding contracts with the regional health authorities, while the others operate independently.

Several of the public psychiatric institutions were converted into district psychiatric centres (DPS) in 2010, or closed down. Public psychiatric care was moved to somatic hospitals, in separate departments. Somatic and psychiatric departments are therefor placed within the same public hospitals. In this survey 9 of the public hospitals invited, were registered as psychiatric hospitals, as these hospitals only contain psychiatric units. The rest of the public hospitals are registered as somatic hospitals, even though several of these also include psychiatric units.

The study includes all 21 local health units including 59 hospitals, where of 50 somatic and 9 psychiatric. All the 21 included private hospitals had more than 10 beds and a funding contract with the regional health authorities by the $31^{\text {st }}$ of December 2010. All together 56 somatic and 24 psychiatric hospitals were invited in the survey.

\section{The questionnaire}

In the beginning of January 2013, a one page-questionnaire was sent to all local health authorities and private hospitals included in the study. All hospitals had been contacted by phone in advance, to provide the name of the most relevant person to receive the questionnaire, usually the manager of medical department. All 21 local health authorities and every private hospital in the survey received one envelope with one numbered questionnaire for each hospital in the health authority. The manager was asked either to answer on behalf of all the hospitals or distribute the questionnaires to relevant receivers. The manager was asked whether or not CAM therapies were offered at the hospital, followed by a list of seven CAM therapies (acupuncture, massage, psychotherapy (not psychologist), art- and expression therapy, alternative diet, other CAM therapies (specified) or no CAM offered). For each mentioned therapy, the name of a contact person was required. Two reminders were sent, both by e-mail.

Out of the 42 envelopes sent, with the total of 93 questionnaires, 49 were filled out and returned after the first dispatch. Four of the local health authorities returned only one questionnaire as they saw themselves as one hospital. Twelve questionnaires were then withdrawn from the survey. One hospital reported no clinical activity, and was also withdrawn, leaving us with 80 questionnaires. Some hospitals returned more than 
one questionnaire, where the questionnaire had been copied into several specimens.

One scheme could for instance claim no CAM use, while another copy with the same scheme number mentioned different CAM modalities in use. In these cases the hospitals were registered in the category of hospitals offering CAM. Nine of the hospitals responded after the first reminder, one after the second reminder. The selection of the studied hospitals is shown in figure 1.

Figure 1: Hospitals participating in the survey.

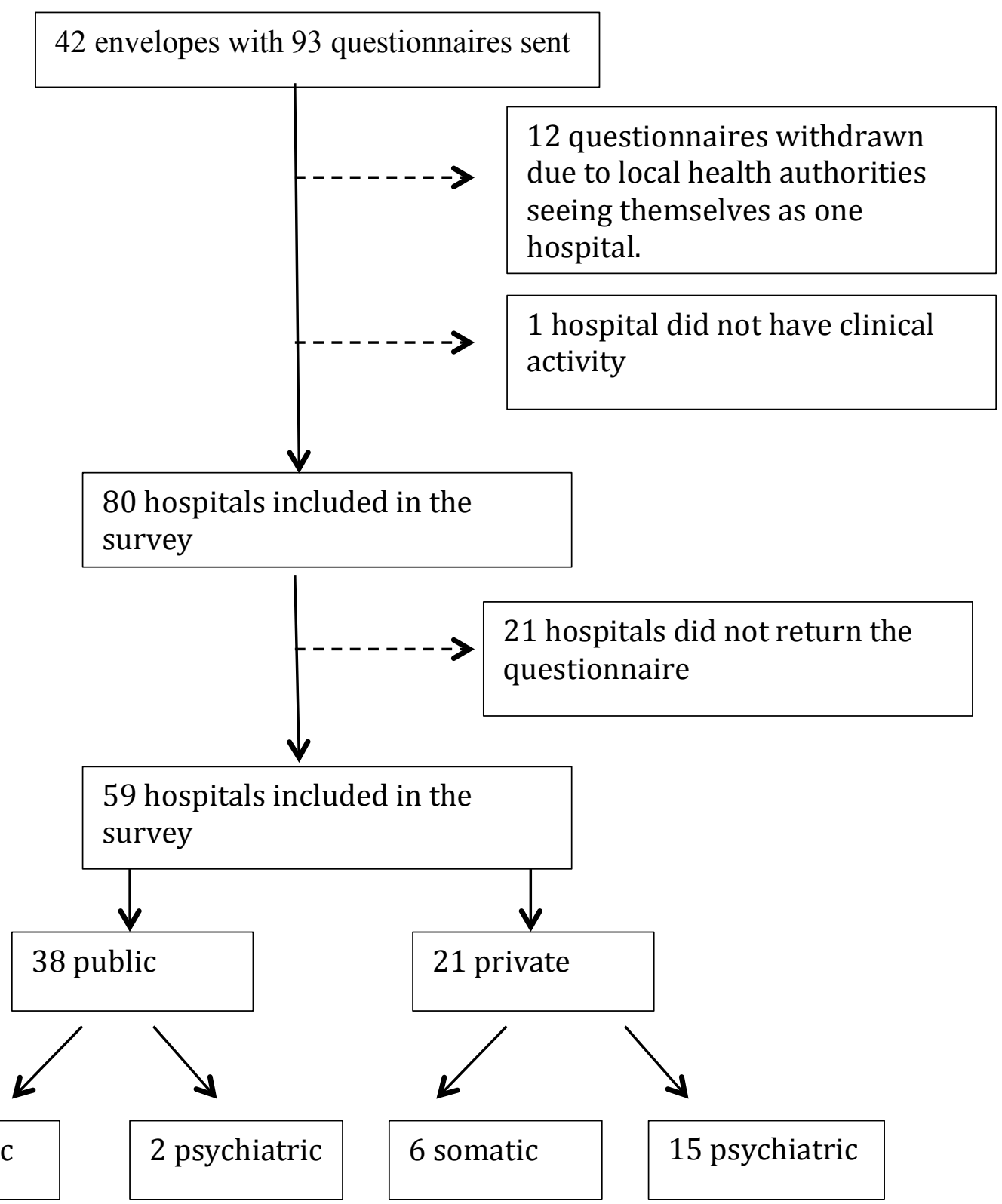


Response rate in public and private hospitals

More private than public hospitals responded to the survey. Of the private hospitals $100 \%$ returned the questionnaire, while $64.4 \%$ of the public. Of the somatic hospitals $75 \%$ responded, compared to psychiatric hospitals with a respondent rate of $70.8 \%$. Among the public somatic hospitals $72 \%$ answered the questionnaire, while only $22.2 \%$ of the public psychiatric hospitals. The respondent rate of the private hospitals was high in both somatic and psychiatric units, $100 \%$ in both (table 1$)$.

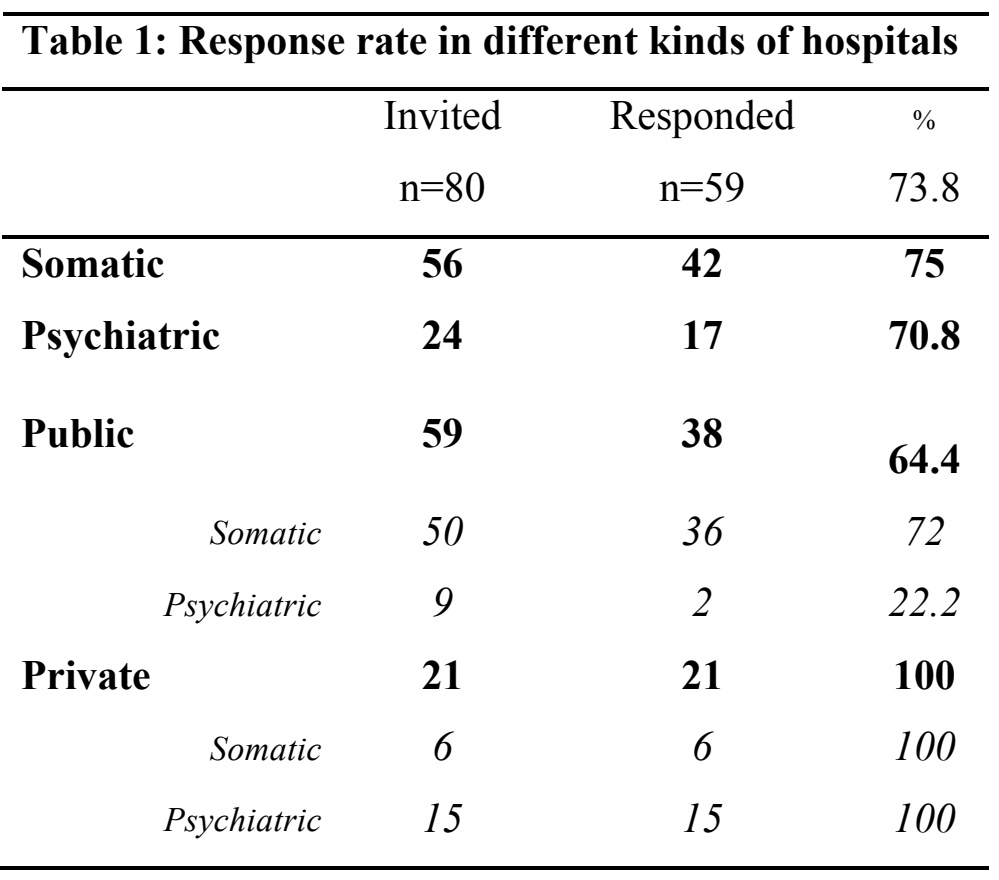

\section{Response rate in different parts of Norway}

We see that health region south (HS) had the highest respondent rate (83.3\%), followed by health region west (HW, 78.9\%) and health region north (HN, 75\%). The respondent rate in middle health region (HM) was 38.5\% (table 2).

\begin{tabular}{|c|c|c|c|}
\hline & Invited $n=80$ & Responded & $\%$ \\
\hline $\mathrm{HN}$ & 12 & 9 & 75.0 \\
\hline $\mathrm{HM}$ & 13 & 5 & 38.5 \\
\hline HW & 19 & 15 & 78.9 \\
\hline HS & 36 & 30 & 83.3 \\
\hline
\end{tabular}




\section{Statistical methods:}

All data were analysed using SPSS version 21.0. Differences between groups were analysed using Pearson's chi-square tests and Fisher exact test.

\section{Ethical approval:}

Because of the survey does not include human information or material, ethical approval was not required.

\section{RESULTS:}

\section{Basic characteristic of the participants:}

A total of 38 public hospitals and 21 private hospitals participated in the study, where of 2 public psychiatric, 15 private psychiatric, 36 public somatic, and 6 private somatic hospitals (table 1).

\section{Norwegian hospitals offering CAM}

A total number of 38 (64.4\%) hospitals reported to offer one or more CAM therapies to their patients (table 3), 24 (63.2\%) of the public hospitals and $14(66.7 \%)$ of the private hospitals $(\mathrm{p}=0.788)$. Slightly more psychiatric hospitals $(76.5 \%)$ than somatic hospitals $(59.5 \%)$ reported such use $(\mathrm{p}=0.218$, table 3$)$, however not at a statistical significant level.

\begin{tabular}{cccc|ccc}
\hline \multicolumn{7}{l}{ Table 3: Hospitals offering CAM in Norway } \\
\hline Total $\mathrm{n}$ & Public $\mathrm{n}$ & Private $\mathrm{n}$ & Somatic $\mathrm{n}$ & Psychiatric $\mathrm{n}$ & \\
$(\%)$ & $(\%)$ & $(\%)$ & $\mathrm{p}=$ & $(\%)$ & $(\%)$ & $\mathrm{p}=$ \\
$38(64.4)$ & $24(63.2)$ & $14(66.7)$ & 0.788 & $25(59.5)$ & $13(76.5)$ & 0.218 \\
\hline
\end{tabular}

\section{CAM offered in somatic and psychiatric hospitals}

CAM was offered in $63.9 \%$ of the public somatic and $50 \%$ of the public psychiatric hospitals in Norway $(\mathrm{p}=0.692)$. More private psychiatric hospitals $(80 \%)$ than private somatic hospitals $(33.3 \%, \mathrm{p}=0.040)$ offered CAM. The highest extent of CAM use was in the private psychiatric hospitals, with $80 \%$ reported use (table 4 ). 


\begin{tabular}{|c|c|c|c|c|}
\hline \multicolumn{5}{|c|}{ Table 4: CAM use within Norwegian hospitals } \\
\hline & Total & Offer CAM & $\%$ & \\
\hline & $\mathrm{n}=59$ & $\mathrm{n}=38$ & 64.4 & p-value \\
\hline Public & 38 & & & \\
\hline Somatic & 36 & 23 & 63.9 & \\
\hline Psychiatric & 2 & 1 & 50 & $\mathrm{p}=0.692$ \\
\hline \multirow{2}{*}{$\begin{array}{l}\text { Private } \\
\qquad \text { Somatic }\end{array}$} & 21 & & & \\
\hline & 6 & 2 & 33.3 & \\
\hline Psychiatric & 15 & 12 & 80 & $\mathrm{p}=0.040$ \\
\hline
\end{tabular}

* Several of the public somatic hospitals also include psychiatric units.

\section{CAM in different parts of Norway}

Highest use of CAM was found in HM where all the five hospitals responding reported to offer CAM at their hospital. The use of CAM in HN and HS was $62.5 \%$ $(\mathrm{n}=5)$ and $68.8 \%(\mathrm{n}=11)$ respectively. In HW only $33.3 \%$ of the hospitals responding $(n=3)$, reported to offer CAM to their patients (table 5).

\section{Table 5: CAM use in different parts of Norway, public}

\section{hospitals}

\begin{tabular}{r|ccccc}
\hline \multicolumn{1}{r}{} & Total & CAM-08 & $\%$ & CAM -13 & $\%$ \\
\hline Public & 38 & & & 24 & 63,2 \\
HN & 8 & 11 & 78,6 & 5 & 62,5 \\
HM & 5 & 5 & 31,3 & 5 & 100 \\
HW & 9 & 6 & 31,6 & 3 & 33,3 \\
HS & 16 & 28 & 56 & 11 & 68,8 \\
\hline
\end{tabular}

If we include the 21 private hospitals, which have funding contracts with the different regional health authorities, the results do not change much (table 6). Of the 21 private hospitals, 14 had funding contracts with HS, 6 with HW, 1 with HN, and none with $\mathrm{HM}$. The use of CAM was reported to be $70 \%$ in $\mathrm{HS}, 66.7 \%$ in $\mathrm{HN}, 40 \%$ in $\mathrm{HW}$ and $100 \%$ in HM. 


\begin{tabular}{|c|c|c|c|}
\hline & Total & CAM yes & $\%$ \\
\hline $\mathrm{HN}$ & 9 & 6 & 66.7 \\
\hline HM & 5 & 5 & 100 \\
\hline HV & 15 & 6 & 40 \\
\hline HS & 30 & 21 & 70 \\
\hline
\end{tabular}

\section{Therapies offered}

Acupuncture is the most commonly offered therapy, offered by $37.3 \%$ of the Norwegian hospitals. Art- and expression therapy is offered in $25.4 \%$ of the hospitals, followed by massage (15.3\%) and alternative diet (8.5\%). Only 5.1\% of the hospitals reported to offer psychotherapy. Also other types of CAM were offered by $27.1 \%$ of the hospitals, such as music therapy, gestalt therapy, hypnosis, acupressure, yoga and mindfulness. Music therapy was the most frequent therapy in this category, offered by $13.6 \%(n=8)$ of the hospitals (table 7$)$.

\begin{tabular}{l|c|c}
\hline Table 7: CAM modalities offered in 2008 and 2013 \\
\hline & \multicolumn{2}{c}{ Offer CAM to patients } \\
\cline { 2 - 3 } & 2008 & 2013 \\
& $\mathrm{n}(\%)$ & $\mathrm{n}(\%)$ \\
\hline Acupuncture & $41(41.4)$ & $22(37.3)$ \\
Massage & $8(8.1)$ & $9(15.3)$ \\
Psychotherapy & $1(1)$ & $3(5.1)$ \\
Art-and Expression & $4(4)$ & $15(25.4)$ \\
Alternative diet & $7(7.1)$ & $5(8.5)$ \\
Other & $7(7.1)$ & $16(27.1)$ \\
No CAM offered & $49(49.5)$ & $21(35.6)$ \\
\hline
\end{tabular}

\section{CAM offered in Norwegian hospitals in 2013 compared to 2008:}

No major differences were found in CAM offered in somatic hospitals in 2013 $(59.5 \%)$ compared to $2008(56.4 \%, p=0.742)$. In psychiatric hospitals, on the other hand, we found an increase from $28.6 \%$ in 2008 to $76.5 \%$ in 2013 ( $\mathrm{p}=0.003$, table 8). 
In 2008 the highest proportion of use was in public somatic hospitals (58\%) [16],

while private psychiatric hospitals offer CAM most frequently in 2013 (80\%, table 4).

\section{Table 8: CAM use in somatic and}

\section{psychiatric hospitals in 2008 and 2013}

\begin{tabular}{lr|c|c|c}
\hline \multicolumn{5}{c}{ Offer CAM to patients } \\
\cline { 3 - 5 } & \multicolumn{1}{c}{ nomatic } & 44 & 2013 & \\
\hline & $\mathrm{n}$ & 56.4 & 25 & \\
& $\%$ & 6 & 59.5 & $\mathrm{p}=0.742$ \\
\hline Psychiatric & $\mathrm{n}$ & 28.6 & 13 & \\
& $\%$ & 50 & 76.5 & $\mathrm{p}=0.003$ \\
\hline Total & $\mathrm{n}$ & 50.5 & 38 & \\
& $\%$ & & 64.4 & $\mathrm{p}=0.089$ \\
\hline
\end{tabular}

No major differences were found in CAM offered in public hospitals in $2013(63.2 \%)$ compared to $2008(61.2 \%, \mathrm{p}=0.842)$. In private hospitals, on the other hand, we found an increase from $28.1 \%$ in 2008 to $66.7 \%$ in 2013 ( $\mathrm{p}=0.006$, table 9).

\section{Table 9: CAM use in public and private hospitals}

\section{in 2008 and 2013}

\begin{tabular}{lr|c|c|l}
\hline & & \multicolumn{2}{|c}{ Offer CAM to patients } \\
\cline { 3 - 5 } & & 2008 & 2013 & p-value \\
\hline Public & $\mathrm{n}$ & 41 & 24 & \\
& $\%$ & 61.2 & 63.2 & 0.842 \\
\hline Private & $\mathrm{n}$ & 9 & 14 & \\
& $\%$ & 28.1 & 66.7 & 0.006 \\
\hline
\end{tabular}

CAM use offered in hospitals in different parts of Norway in 2008 compared to 2013 show an increase in hospitals offering CAM in HM from 31.3\% in 2008 to $100 \%$ in 2013 ( $\mathrm{p}=0.012$ ). Smaller increases were found in HW and HS, and a small decrease in $\mathrm{HN}$, however not at a significant level (table 10). 


\begin{tabular}{|c|c|c|c|}
\hline \multirow{2}{*}{\multicolumn{4}{|c|}{$\begin{array}{l}\text { Table 10: CAM use in different pa } \\
\text { versus 2013, public hospitals } \\
\text { Offer CAM to patients }\end{array}$}} \\
\hline & & & \\
\hline & 2008 & 2013 & $\mathrm{p}$-value \\
\hline \multirow[t]{2}{*}{$\mathrm{HN}$} & 11 & 6 & \\
\hline & 78.6 & 66.7 & 0.643 \\
\hline \multirow[t]{2}{*}{ HM } & 5 & 5 & \\
\hline & 31.3 & 100 & 0.012 \\
\hline \multirow[t]{2}{*}{ HW } & 6 & 6 & \\
\hline & 31.6 & 40 & 0.610 \\
\hline \multirow[t]{2}{*}{ HS } & 28 & 21 & \\
\hline & 56 & 70 & 0.213 \\
\hline \multirow[t]{2}{*}{ Total } & 50 & 38 & \\
\hline & 50.5 & 64.4 & 0.089 \\
\hline
\end{tabular}

In $200813.1 \%(n=13)$ of the hospitals offered more than one CAM therapy, while $25.9 \%(n=15)$ did this in 2013. All CAM modalities were offered in more hospitals in 2013 than in 2008, except for acupuncture, which had decreased from $41.4 \%(n=41)$ in 2008 to $37.3 \%(n=22)$ in 2013. Art- and expression therapy has had the most prevailing increase, from $4 \%(n=4)$ in 2008 to $25.4 \%(15)$ in 2013.

In 2008 the public somatic hospitals were most likely to offer CAM, while the opposite was shown in 2013, where private psychiatric hospitals were most likely to offer CAM [16]. CAM was offered within half of the somatic hospitals in 2008 showing a minor increase in 2013. A more pronounced change was shown within private hospitals, where less than one out of 3 private hospitals offered CAM in 2008, and 2 out of 3 reported to offer CAM in 2013. Private hospitals show the largest increase of CAM from $28.1 \%$ (2008) to $66.7 \%$ (2013). A big difference between public and private hospitals was shown in 2008, while the 2013 survey showed less diversification. 


\section{DISCUSSION:}

We found that $64.4 \%$ of the hospitals in this study offered CAM to their patients. Private psychiatric hospitals offered CAM most frequently, and the apportionment of use varied throughout the country. West part of Norway seemed to offer CAM less often than the rest of the country, while hospitals in Mid-Norway seemed to offer CAM more often. The use of CAM has increased substantially between 2001 (25\%) and 2013 (64.4\%). While there has been a doubling of hospitals offering CAM between 2001 and 2008, the increase from 2008 to 2013 is $13.9 \%$.

\section{Bias considerations}

The respondent rate of $73.8 \%$ (table 1) is somewhat lower than what was the case in 2001 (94\%) and 2008 (85\%). The lower response rate in this study might be due to a different organization of the public hospitals in 2013, where one manager has responsibility for several local hospitals, with different locations and with several units. This might lead to a lower overview of CAM modalities in use for the doctor in charge. The presumed lack of overview of therapy methods offered could probably also have resulted in under-reporting of CAM.

The fact that the reminders were sent by e-mail instead of by mail, as they were in 2001 and 2008, could possibly have influenced the response rate as well, because it probably might be easier to oversee an e-mail than an envelope in the mail. We do have, on the other hand a rather high response rate in this study, ensuring a representative sample of Norwegian hospitals.

Integration of CAM within the conventional health service is associated with different perspectives, attitudes and points of view. Due to this we cannot exclude the possibility that the hospitals most positive to CAM answered more frequently than those who are more sceptical. It could be that the receiver of the questionnaire did answer on behalf of own standpoint in which CAM should be offered in conventional hospitals, instead of the actual practise. This possibility will go both ways, resulting in both a conceivable over-estimate or an under-estimate of CAM offered within hospitals, but is not likely to be differential between groups. 


\section{Comparison of CAM offered within different types of hospitals}

The comparison of CAM offered within somatic and psychiatric hospitals might be a bit inaccurate, due to the fact that many public somatic hospitals also include psychiatric units, and then again offer CAM within these units. However, most of the public somatic hospitals that reported offering of CAM within psychiatric units, also reported to offer CAM within somatic units. Even thou they also offer CAM within psychiatric units we have registered the hospitals as somatic in our analyses.

\section{Comparison of CAM offered within different parts of Norway}

An increase in offering of CAM was reported in all regional health authorities, except North of Norway, which reported a decrease. The increase in Mid-Norway where all responding hospitals offered CAM could be due to the low response rate $(n=5$, $38.5 \%$ ). CAM offered in HM in 2008 was also reported by 5 hospitals, but according to higher response rate, the reported use was $31.3 \%$ (table 10). If we assume that none of the non-responders in HM offered CAM, there would still be an increase, somewhat small, from $31.3 \%$ to $38.5 \%$.

\section{Comparison of CAM offered within Norwegian hospitals in 2008 and 2013:}

Our findings of slightly more hospitals offering CAM in 2013 than in 2008 could be resulted by a lower response rate, causing a higher number of answers from hospitals offering CAM. If all the non-responders did not offer CAM, the number of Norwegian hospitals offering CAM would have been $47.5 \%$, resulting in a decrease from 2008 by $3 \%$ and not an increase in hospitals offering CAM.

However when comparing the two studies, we must keep in mind that there has been changes in the division of hospitals over the last years. Several of the smaller public hospitals have been merged together to create fewer, bigger hospitals. In 2008 more of the private hospitals were included in the survey, while in 2013 only the private hospitals with more than 10 beds and a funding contract with the government were included [16]. This led to fewer hospitals included in the survey in 2013 compared to 2008. It is possible that the changes in hospital division and structure, has influenced the results in one way or another. There could for instance be a possible underreporting of CAM use in the biggest hospitals due to less overview by the manager, of CAM offered within different departments. 


\section{Trends in attitudes towards CAM:}

The increase in hospitals offering CAM from 2001 to 2013 might be caused by a remarkable increase of CAM use in the general population during the beginning of the $21^{\text {st }}$ century $[1-3,9]$. Health care workers general attitude towards CAM have also become more positive, and more of them wish to deduct CAM into health care and hospitals $[9,10]$. The significant increase of CAM offered within Norwegian hospitals might be due to the increased interest of CAM use in the population, and an increased request for CAM from patients. The health care workers interest might also have influenced, as health care workers with training within CAM therapies seem to be allowed to practice these therapies in the hospital $[10,11,19,20]$.

\section{Comparison with other studies:}

Many surveys worldwide have studied CAM use among the general population and in different patient groups $[5,6,20,21]$. Few seem to have studied CAM use provided within hospitals [16-18]. In the Norwegian survey from 2008, referred to earlier in this article, data about CAM use in Denmark were included [16]. Our findings showed a higher extent of hospitals offering CAM compared to the Danish and Swiss survey $[16,17]$. However the reason for this could be that these surveys were published a few years ago. In the Norwegian survey from 2008, and in both Denmark and Switzerland, acupuncture was reported as the most offered discipline. This is in accordance with our findings. Other than these, no other commensurable studies were found.

\section{CONCLUSION:}

The total number of Norwegian hospitals offering CAM has had a significant increased since 2001, and there has been an increase in use both within somatic and psychiatric hospitals, public and private hospitals. Little is known about the extent of use within each hospital, only whether they offer CAM or not. Future research is needed to find out which departments CAM is offered within the hospitals, and to what extent CAM is used within each hospital. 


\section{References}

1. Fonnebo, V. and Launso, L., High use of complementary and alternative medicine inside and outside of the government-funded health care system in Norway. J Altern Complement Med, 2009. 15(10): p. 1061-6.

2. Stange, R., Amhof, R. and Moebus, S., Complementary and alternative medicine: attitudes and patterns of use by German physicians in a national survey. J Altern Complement Med, 2008. 14(10): p. 1255-61.

3. Opheim, R., et al., Use of complementary and alternative medicine in patients with inflammatory bowel disease: results of a cross-sectional study in Norway. Scand J Gastroenterol, 2012. 47(12): p. 1436-47.

4. Hanssen, B., et al., Use of complementary and alternative medicine in the Scandinavian countries. Scand J Prim Health Care, 2005. 23(1): p. 57-62.

5. Adams, D., et al., Complementary and alternative medicine use by pediatric specialty outpatients. Pediatrics, 2013. 131(2): p. 225-32.

6. Ali-Shtayeh, M.S., Jamous, R.M. and Jamous, R.M., Complementary and alternative medicine use amongst Palestinian diabetic patients. Complement Ther Clin Pract, 2012. 18(1): p. 16-21.

7. Harris, P.E., et al., Prevalence of complementary and alternative medicine (CAM) use by the general population: a systematic review and update. Int J Clin Pract, 2012. 66(10): p. 924-39.

8. Fønnebø, V., NAFKAM-undersøkelsen 2012, [The NAFKAM Study] [cited 2013; Available from:

http://nifab.no/om_alternativ_behandling/tall_og_fakta/nafkam_underso ekelsen_2012.

9. Nyborg, L. and Launsø L., Utprøvinger av alternativ behandling innenfor helsevesenet i møte mellom helsepersonell og alternative behandlere [Tryout of alternative therapies in health care in the meeting between health professionals and alternative practitioners]. 
Vol. nr 5. 2007, Tromsø: Nasjonalt forskingssenter innen komplementær og alternativ medisin.

10. Risberg, T. and Kolstad A., Alternativ medisin - holdninger og bruk blant sykehusansatte leger, sykepleiere og kontorpersonell i NordNorge, [Alternative medicine-attitudes and use among physicians, nurses and administrative staff employed in hospitals in northern Norway]. Tidsskr Nor Laegeforen, 2003. 123(5): p. 604-6.

11. Johnson, P.J., et al., Personal use of complementary and alternative medicine (CAM) by U.S. health care workers. Health Serv Res, 2012. 47(1 Pt 1): p. 211-27.

12. Knutson, L., Johnson, P.J., Sidebottom, A. and Fyfe-Johnson, A., Development of a hospital based integrative healthcare program. 2013. 43(2): p. 101-7.

13. Aanjesen, T., et al., Akupunktur - et supplement i allmennpraksis, [Acupuncture-a complementary treatment in general practice]. Tidsskr Nor Laegeforen, 2002. 122(9): p. 921-3.

14. Kozak, L.E., et al., Use of complementary and alternative medicine (CAM) by Washington State hospices. Am J Hosp Palliat Care, 2008. 25(6): p. 463-8.

15. Norheim, A.J., Integrert medisin i London, [Integrated medicine in London]. Tidsskr Nor Laegeforen. 2011 Apr 8;131(7):714-5

16. Salomonsen, L.J., et al., Use of complementary and alternative medicine at Norwegian and Danish hospitals. BMC Complement Altern Med, 2011. 11: p. 4.

17. Widmer, M., et al., The supply of complementary and alternative medicine in Swiss hospitals. Forsch Komplementmed, 2006. 13(6): p. 356-61.

18. Salomonsen, L.J., Grimsgaard, S. and Fønnebø, V., Bruk av alternativmedisinsk behandling ved norske sykehus, [Use of alternative medicine in Norwegian hospitals]. Tidsskr Nor Laegeforen, 2003. 123(5): p. 631-3.

19. Shorofi, S.A. and Arbon, P., Nurses' knowledge, attitudes, and professional use of complementary and alternative medicine (CAM): a 
survey at five metropolitan hospitals in Adelaide. Complement Ther Clin Pract, 2010. 16(4): p. 229-34.

20. Brown, S., Use of complementary and alternative medicine by physicians in St. Petersburg, Russia. J Altern Complement Med, 2008. 14(3): p. 315-9.

21. Shorofi, S.A., Complementary and alternative medicine (CAM) among hospitalised patients: reported use of CAM and reasons for use, CAM preferred during hospitalisation, and the socio-demographic determinants of CAM users. Complement Ther Clin Pract, 2011. 17(4): p. 199-205. 